\title{
The best of 25 years: mRNA 3'end processing
}

\author{
INA HOLLERER ${ }^{1,2,3}$ and ANDREAS E. KULOZIK ${ }^{1,2}$ \\ ${ }^{1}$ Department of Pediatric Oncology, Hematology and Immunology, University of Heidelberg, 69120 Heidelberg, Germany \\ ${ }^{2}$ Molecular Medicine Partnership Unit (MMPU), 69117 Heidelberg, Germany \\ ${ }^{3}$ European Molecular Biology Laboratory Heidelberg (EMBL), 69117 Heidelberg, Germany
}

In the last 25 years, research on mRNA $3^{\prime}$ end processing has been an exciting growing field. Studying the polyadenylation complex in its function, biochemistry, and structure enabled an in-depth look at constitutive $3^{\prime}$ end processing. More recent data have revealed that regulated mRNA $3^{\prime}$ end processing contributes to important physiological pathways, including differentiation or innate immunity, but, if deregulated, potentially causes diseases, such as thrombophilia or even cancer.

A quarter-century ago research in mRNA $3^{\prime}$ end processing was just emerging as an attractive field: Publications of James Manley's and Walter Keller's labs addressed the interaction between the poly(A) (polyadenylation) signal and its cognate mRNA binding proteins (RBPs), giving a first idea about the mechanisms regulating the $3^{\prime}$ end processing step of mRNA maturation; reports from the Proudfoot and Higgs labs showed that mutations of the poly(A) signal can cause genetic disease, hinting at the medical impact of deregulated $3^{\prime}$ end formation even before the processing machinery had been identified; Brown and Morrison reported that alternative polyadenylation (APA) influenced the immunoglobulin heavy chain (IgH) class switch, highlighting, for the first time, the important role of APA in human physiology. Although the data obtained 25 years ago remain valid, progress in methodology including high-throughput techniques and in-vivo analyses of RNA-protein interactions helped to gain major new insights into a more global picture of mRNA $3^{\prime}$ end processing. Furthermore, data by a number of different research groups including the Manley and Karin labs but also our own highlighted regulated $3^{\prime}$ end formation as a way to post-transcriptionally adjust mRNA levels as an essential mechanism in human physiology and, if deregulated, of human disease. Clearly, mRNA processing revealed itself as a complex mechanism that was so much more than a boring constitutive step of mRNA maturation thus adding a completely new flavor to gene expression control.

Corresponding author: andreas.kulozik@med.uni-heidelberg.de Article and publication date are at http://www.rnajournal.org/cgi/doi/ 10.1261/rna.050062.115. Freely available online through the RNA Open Access option.

\section{Constitutive mRNA 3'end processing}

Biochemical as well as computational analyses have been contributing immensely to our current knowledge about how pre-mRNA $3^{\prime}$ end processing works. To understand the underlying molecular mechanism, numerous groups investigated the structure and composition of the polyadenylation complex, the machinery that cleaves and subsequently adds a poly(A) tail to all mRNA, except to those encoding histones. In the early '90s, the finding that CstF (cleavagestimulation factor) can stimulate polyadenylation in vitro represented an important first piece of a large puzzle-we know now that a network of $\sim 20$ core plus numerous accessory proteins ensure efficient mRNA $3^{\prime}$ end processing and link polyadenylation to other steps in the pathway of mRNA biogenesis. Researchers in James Manley's lab provided first insights into the architecture of the core human $3^{\prime}$ end processing complex by electron microscopy analyses, but because of its size and complexity we currently lack high-resolution 3D structural information of the complete machinery. Since $\sim 70 \%$ of pre-mRNAs possess more than one functional poly(A) site, it also remains to be worked out whether all of these sites recruit the same protein complex; knockdown experiments of core $3^{\prime}$ end processing factors pointed into a different direction. Reducing the abundance of these proteins did not abolish polyadenylation but shifted it to other poly(A) sites, indicating that the overall composition of the polyadenylation machinery differs between poly(A) sites. Over the years, studies have identified increasing numbers of RBPs to participate in mRNA $3^{\prime}$ end processing. As highlighted by Maniatis and Reed, many of these RBPs have formerly been known to be involved in other steps of RNA biogenesis such as splicing or transcription, which revealed that $3^{\prime}$ end processing is embedded within a complex network ensuring a tight spatial and temporal interconnection of different processes. To date, the list of factors ensuring accurate polyadenylation of pre-mRNAs has been constantly expanding, bringing the field a big step closer to understanding the details of the mechanistic principles of mRNA $3^{\prime}$ end processing.

(C) 2015 Hollerer and Kulozik This article, published in RNA, is available under a Creative Commons License (Attribution-NonCommercial 4.0 International), as described at http://creativecommons.org/licenses/by-nc/4.0/. 


\section{Regulated mRNA 3'end processing and the medical perspective}

The recognition of regulated $3^{\prime}$ end processing as a means to fine-tune gene expression on a post-transcriptional level certainly represents one of the most significant advances in the field in the last 25 years, not least because of its impact on human pathophysiology. In recent years, studies have focused on examining the mechanisms that control the polyadenylation process. In a very recent paper, researchers from the Manley lab found the proteins RBBP6 (retinoblastoma-binding protein 6) and its single-domain isoform iso3 to compete in binding to the core $3^{\prime}$ end processing machinery, thereby influencing transcript levels, especially of genes with AUrich $3^{\prime}$ UTRs. A similar RBP switch has also been reported earlier by our own lab to occur on a conserved cis-acting element, referred to as the Upstream Sequence Element (USE) of the prothrombin RNA. This protein is a protease and serves key functions, amongst others, in regulating blood coagulation, complement activation and angiogenesis. The USE-dependent RBP switch changes the composition of the $3^{\prime}$ end processing complex in a stress-dependent fashion thereby upregulating polyadenylation efficiency and prothrombin biosynthesis. In general, quantitatively regulating $3^{\prime}$ end processing by external stimuli offers an attractive and faster alternative to transcriptional bursts in upmodulating gene expression by providing the chance to fine-tune gene expression levels according to cellular needs. Beyond that, the work of many labs has recently shown that alternative polyadenylation occurs in response to external stimuli or in disease. Mechanistic studies found various RNA-binding proteins to influence poly(A) site selection, as exemplified by the splicing-regulating SR proteins and U1SNRNP, which globally stimulates alternative polyadenylation. Besides that, regulated $3^{\prime}$ end processing can also take place independent of the polyadenylation step. In this respect, the formation of histone mRNA-ends has been a particularly interesting case. As has chiefly been worked out by the Marzluff lab, histone $3^{\prime}$ ends lack a poly(A) tail but are processed by a mechanism differing from the canonical cleavage and polyadenylation step. Interestingly, histone mRNA levels fluctuate in a cell cycle-dependent fashion with regulated $3^{\prime}$ end processing, among transcriptional effects, contributing to these changes in histone gene expression.

In the 80s, Doug Higgs and Nick Proudfoot reported a point-mutation of the poly(A) site to cause $\alpha$-thalassemia. This finding elegantly demonstrated to what extent $3^{\prime}$ end processing can impact normal gene function and highlighted its role in medicine. To this day, data from many labs have shown that deregulated $3^{\prime}$ end processing can result in diseases, ranging from a particularly common predisposition to develop thromboembolism (when physiologically inefficient $3^{\prime}$ end processing of the prothrombin mRNA is gaining function) to rare but devastating conditions such as the fragile $\mathrm{X}$ syndrome or myotonic dystrophy (when polyadenylation takes place at wrong sites). Extending the pioneering work by Brown and Morrison, studies from a number of research groups have revealed regulated $3^{\prime}$ end mRNA processing to play a role in various physiological pathways as exemplified by the results of highly parallel RNA sequencing methods uncovering $3^{\prime}$ UTR lengthening/shortening by alternative polyadenylation to control cellular development, proliferation, and differentiation. Recent studies have also reported deregulated histone $3^{\prime}$ end formation to cause diseases, e.g., spinal muscular atrophy (SMA) as described by Tisdale and colleagues, just to mention an example.

Inevitably, when it became clear that deregulated $3^{\prime}$ end processing can trigger diseases, it entered clinical research. Differences observed in polyadenylation patterns between healthy and tumor tissue indicated that deregulated $3^{\prime}$ end processing may play a role in cancerogenesis or in the progression of cancer. Advanced technical and analytical tools may be useful as diagnostic or prognostic biomarkers to detect recurrent $3^{\prime}$ end processing abnormalities and abnormal alternative polyadenylation patterns in cancer. Coupled with an improved in-depth future understanding how normal $3^{\prime}$ end processing and abnormal $3^{\prime}$ end formation in disease mechanistically differ, interfering with the latter might potentially offer new perspectives for innovative treatment strategies that aim at restoring normal processing or at eliminating cells that display abnormalities. However, before this can be accomplished we need to know which physiological functions are modulated by regulated $3^{\prime}$ end processing and how this is it regulated in vivo. Once these issues have been resolved, we can start pondering how to clinically approach $3^{\prime}$ end processing-associated diseases in a logical fashion.

Although important insight has been gained by major research efforts by many labs, we still poorly understand the role of regulated $3^{\prime}$ end processing in human physiology. We also lack detailed mechanistic knowledge about the process regulating the cleavage and the polyadenylation step. However, considering the constant scientific progress over the last 25 years we can sure look forward to exciting new developments in this field within the next 25 years-certainly, the RNA journal will continue to keep us posted! 

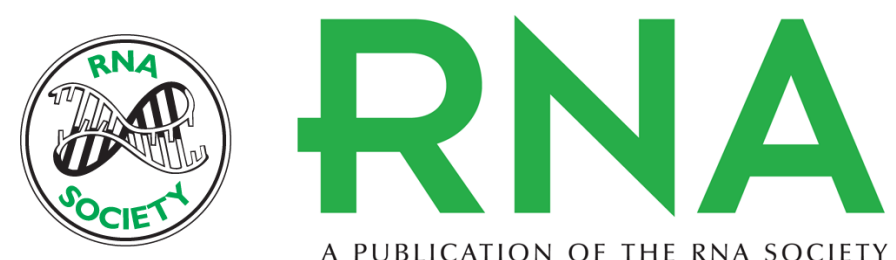

A PUBLICATION OF THE RNA SOCIETY

\section{The best of 25 years: mRNA 3'end processing}

Ina Hollerer and Andreas E. Kulozik

RNA 2015 21: 640-641

Open Access Freely available online through the RNA Open Access option.

Creative This article, published in RNA, is available under a Creative Commons License

Commons (Attribution-NonCommercial 4.0 International), as described at

License http://creativecommons.org/licenses/by-nc/4.0/.

Email Alerting Receive free email alerts when new articles cite this article - sign up in the box at the Service top right corner of the article or click here.

To subscribe to $R N A$ go to:

http://rnajournal.cshlp.org/subscriptions

(C) 2015 Hollerer and Kulozik; Published by Cold Spring Harbor Laboratory Press for the RNA Society 